\title{
UMA LEITURA DA OBRA “PEDAGOGIA HISTÓRICO-CRÍTICA, PRIMEIRAS APROXIMAÇÕES", DE DERMEVAL SAVIANI
}

\author{
FLÁVIA DANIELA BOSI LEAL* \\ BENÍCIO JOSÉ DE OLIVEIRA FILHO**
}

\begin{abstract}
RESUMO
O presente texto apresenta aspectos importantes da obra "Pedagogia Histórico-Crítica, primeiras aproximações", escrita por Demerval Saviani em 2013. Os fundamentos filosóficos, psicológicos e didático-pedagógicos contidos na obra foram discutidos no presente artigo a fim de demonstrar as importantes contribuições dessa teoria para o debate atual acerca da educação.

Palavras-chave: Pedagogia histórico-crítica, Educação, Teorias pedagógicas
\end{abstract}

\section{INTRODUÇÃO}

A obra "Pedagogia Histórico-Crítica, primeiras aproximações”, de Dermeval Saviani (2013), presenta, dentro da perspectiva que será adotada neste artigo, reflexões necessárias e urgentes a respeito do papel da escola no contexto da educação. Seu arcabouço teórico não é simples, e foi desenvolvido e aprimorado ao longo do tempo. Essa jornada será apresentada a fim de trazer luz aos aspectos que consideramos fundamentais para compreender as críticas e propostas contempladas por essa teoria.

* Mestranda em Educação na Universidade Metodista de São Paulo e Master Coach pela Febracis. Professora especialista em Metodologias Ativas para a Educação (PUC/MG).

** Mestrando pela Universidade Metodista de São Paulo na área de Educação e pós-graduado em Psicanálise pelo Instituto Kadmon de Psicanálise. Atualmente está em processo de conclusão do curso de bacharelado em Filosofia pela universidade Salesiana Dom Bosco 


\section{VISÃO DA OBRA AO LONGO DO TEMPO}

A primeira formulação do que viria a se desdobrar na pedagogia histórico-crítica data de 1982, com o artigo "Escola e democracia: para além da curvatura da vara". Somente em 1984 adotou-se a denominação "pedagogia histórico-crítica" que se difundiu, principalmente com a publicação, em 1991, do livro "Pedagogia histórico-crítica: primeiras aproximações", livro esse que reuniu um conjunto de estudos produzidos entre 1984 e 1988.

Em 2003, o livro teve sua oitava edição ampliada com o acréscimo de dois novos estudos: "A materialidade da ação pedagógica e os desafios da pedagogia histórico-crítica”, resultante da conferência de encerramento do Simpósio "Dermeval Saviani e a educação brasileira" realizado na UNESP de Marília em 1994; e "Contextualização histórica e teórica da pedagogia histórico-crítica”, redigido a partir de uma entrevista concedida à Associação dos Professores do Paraná em 1997. Desde então foram publicadas novas edições mantendo a linha de conteúdo, e neste trabalho, utilizamos a $11^{\circ}$ edição como fonte de estudo e pesquisa.

\section{CONTEXTO HISTÓRICO DA OBRA "PEDAGOGIA HISTÓRICO CRÍTICA"}

Percebemos, pelo contexto apresentado, que a proposta da pedagogia histórico-crítica passou por um período de maturação até alcançar o formato pelo qual a conhecemos hoje. O cuidado em se reestruturar, adicionar capítulos e promover o desdobramento de suas teses a torna deveras atualizada e, para que se possa ter ainda uma melhor compreensão de sua mensagem, também se faz necessário considerar o contexto histórico no qual ela foi articulada.

Estamos falando, pois, do contexto das lutas de resistência à ditadura militar que se travavam no Brasil, nas décadas de 1970 e 1980, com destaque para os movimentos estudantis, que atuavam por meio de suas organizações representativas. No ano de 1968, por exemplo, se por um lado foi decretado o Ato Institucional 
$\mathrm{n}^{\circ}$ 5, que nas palavras do próprio Saviani: "foi um dispositivo draconiano por meio do qual a ditadura se tornou mais rígida, abolindo direitos, fechando o congresso" SAVIANI (2014, p. 12), também nesse ano ocorreram as manifestações estudantis em nível mundial tendo como epicentro Paris, com a tentativa de promover uma revolução social pela revolução cultural.

Toda essa grande mobilização ficou conhecida no Brasil como Movimento de Maio de 68. Embora tenha chegado, de fato, a ameaçar a ordem existente, toda essa luta contra a tecnoburocracia, na verdade, não surtiu os efeitos que se esperavam e a propalada revolução social pela revolução cultural não ocorreu nos termos desejados.

\section{INTRODUÇÃO AO DEBATE: “SOBRE A NATUREZA E ESPECIFICIDADE DA EDUCAÇÃO”}

Mais adiante, apresentaremos as teorias educacionais predominantes nessa etapa histórica. No entanto, para que entremos em contato com elas já considerando o entendimento sobre a essência reveladora da pedagogia histórico crítica, propomos atentar, primeiramente, para a questão posta por Saviani, no que tange à natureza e à especificidade da educação.

$\mathrm{E}$, nada mais motivante que iniciar esse debate a partir da seguinte afirmação:

A natureza humana não é dada ao homem mas é por ele produzida sobre a base da natureza biofísica. Consequentemente, o trabalho educativo é o ato de produzir, direta e intencionalmente, em cada indivíduo singular, a humanidade que é produzida histórica e coletivamente pelo conjunto dos homens. (SAVIANI, 2013, p. 6)

É possível tomarmos tal afirmativa como respaldo para o seguinte desdobramento proposto por Saviani (2013) de que, embora a natureza da educação seja o saber - fruto do "trabalho 
não material" -, os diferentes tipos de saberes não interessam em si mesmos, eles interessam sim, enquanto elementos que os indivíduos da espécie humana necessitam assimilar para que se tornem humanos. E daí a importância dos processos educativos que possibilitem a sistematização do saber objetivo, construído historicamente, e, inicialmente manifesto como o próprio ato de viver, assumindo, posteriormente, um caráter institucionalizado, tal como sabemos hoje: a escola.

A passagem da escola à forma dominante de educação coincide, pois, com a etapa histórica em que as relações sociais, mediadas pela cultura (o mundo produzido pelo homem) passaram a prevalecer sobre as relações naturais. Como consequência, ocorreu a predominância do saber metódico, sistemático, científico, sobre o saber espontâneo, "natural" e assistemático, de modo que a especificidade da educação passa a ser determinada pela forma escolar.

\section{COMPREENDENDO AS TEORIAS DA EDUCAÇÃO}

Neste ponto, convém abordar as diferentes teorias vigentes no contexto da elaboração da pedagogia histórico-crítica. Vamos dividi-las, conforme também adotou Saviani em seu artigo de 2014, "A Pedagogia Histórico-Crítica", em dois blocos: as teorias crítico-reprodutivistas e as teorias não críticas.

\section{TEORIAS CRÍTICO-REPRODUTIVISTAS: \\ A EDUCAÇÃO REPRODUZ, E NÃO TRANSFORMA A SOCIEDADE}

Segundo Saviani (2014) a visão crítico-reprodutivista surgiu basicamente a partir das consequências do fracasso do movimento de maio de 1968, com a predominância da perspectiva tecnocrático-autoritária sobre os diferentes interesses da sociedade. Tendo isso em vista, entende-se o porquê de sua tendência a buscar evidenciar a impossibilidade de se fazer uma revolução social pela revolução cultural, em uma sociedade capitalista. 
Dentro desse arcabouço teórico Saviani (2014) destaca as seguintes obras e autores: "Ideologia e Aparelhos Ideológicos de Estado, notas para uma investigação", de Althusser (1970); "A reprodução: elementos para uma teoria do sistema de ensino", de Bourdieu e Passeron (1970); e "L' école capitaliste en France", de Baudelot e Establet (1970), em que eles vão demonstrar que a escola é uma instituição subordinada ao capital e daí a denominação escola capitalista, conforme observa Saviani (2014).

Tanto as três obras mencionadas - de Althusser (1970), Baudelot e Establet (1970), Bourdieu e Passeron (1970) - como uma publicada no livro Schooling in Capitalist America, dos americanos Bowles \& Gintis (1977) são consideradas teorias da educação, segundo Saviani (2014) na medida em que se empenham em explicar como funciona a educação e de que modo se relacionam com a forma de sociedade na qual ela é instituída. No entanto, não estão preocupadas em orientar a ação educativa, não contemplando, portanto, uma preocupação pedagógica. Fica, então, uma lacuna sobre como atuar no campo educativo de forma a promover algum tipo de transformação a partir da educação.

\section{TEORIAS NÃO CRÍTICAS}

Compreendendo que as teorias reprodutivistas não contemplavam a prática educativa, Saviani (2014) empreendeu uma análise das teorias pedagógicas vigentes, identificando três grandes manifestações: a pedagogia tradicional (centrada no professor), de modo que a iniciativa cabia ao professor que era, ao mesmo tempo, o sujeito do processo, o elemento decisivo e também decisório; a pedagogia nova (centrada no aluno), cuja iniciativa se desloca para o aluno; e a pedagogia tecnicista (centrada no método), na qual o elemento principal passa a ser a organização racional dos meios, ocupando o professor e o aluno uma posição secundária.

Essas teorias foram batizadas por Saviani (2014), no livro "Escola e Democracia", Saviani (2009), de teorias não-críticas. 
Compreendendo criticidade como a clareza da relação entre educação e sociedade, e da dependência da educação em relação à sociedade na qual ela é instituída, nada mais lógico do que considerar tais teorias como não-críticas, justamente porque não contemplam essa percepção.

\section{PEDAGOGIA HISTÓRICO-CRÍTICA: PRESSUPOSTOS E ESTRUTURA}

Apresentou-se, nas teorias de Saviani, contudo, um contexto teórico no qual, por um lado, se admitia que se o papel da educação é reproduzir a sociedade, então, qualquer que seja o tipo de educação que se desenvolva, ela vai sempre a estar reproduzindo. Logo, é impossível uma educação que tenha algum influxo transformador sobre a sociedade. Por outro, tendia-se a colocar a possibilidade de uma educação transformadora no âmbito da própria sociedade, dos movimentos sociais e de classe, e nesse sentido secundarizando, quando não desvalorizando, o papel da escola, no que Saviani chama de "visões emancipadoras da educação".

Daí, a oposição entre teoria e prática, que está sempre presente no campo educacional. Seu suporte é o raciocínio formal: se é teoria não é prática, e se é prática não é teoria. E foi exatamente para resolver essas dicotomias que Saviani foi impelido a elaborar uma nova teoria que superasse a limitação lógico-formal das teorias pedagógicas correntes.

Elaborando a crítica dessas teorias, Saviani percebeu o seguinte problema: seria possível construir uma teoria crítica da educação, portanto uma teoria que tenha consciência dos determinantes sociais e que não fosse reprodutivista? Ou seja, que pudesse orientar a ação dos educadores, dos professores, num sentido transformador? A resposta por ele elaborada foi justamente a formulação da Pedagogia histórico-crítica.

Para a Pedagogia histórico-crítica, portanto, a educação insere-se na sociedade e é por ela determinada, participando 
desse movimento contraditório, SAVIANI (2013). Vale refletir que o saber se converteu, com a sociedade capitalista, em força produtiva, em meio de produção; e como nessa sociedade os meios de produção são propriedade privada, entende-se a dificuldade que a sociedade capitalista tem de estender o saber para todos. Dentro dessa perspectiva, essa possibilidade do saber para todos passa pela mudança dessa sociedade, ou seja, pela socialização dos meios de produção que implica a construção de uma sociedade que supere a ordem capitalista.

Nessa linha, é possível perceber o que Saviani denominou como HISTÓRICO, embasado no materialismo histórico, dialético, que ultrapassa a lógica formal. Bem como, já aponta para o que ele quis dizer como CRÍTICA, uma vez que evidencia as relações entre a educação e a sociedade. Cabe, agora, nos debruçarmos em entender qual o caráter pedagógico proposto por Saviani.

Nesse sentido, e considerando a especificidade da educação, para Saviani, a escola diz respeito ao conhecimento elaborado e não ao conhecimento espontâneo; ao saber sistematizado e não ao saber fragmentado; à cultura erudita e não à cultura popular, de modo que a prática de transformação possa ocorrer a partir do momento que se dá acesso às ferramentas de argumentação estruturada e conhecimento científico e cultural, para que as massas possam fazer as suas reivindicações.

\section{A APROXIMAÇÃO ENTRE AS TEORIAS DENOMINADAS POR SAVIANI (2013) COMO: POMO DA DISCÓRDIA E O FRUTO PROIBIDO ${ }^{1}$}

Percebendo a possibilidade de que sua visão contribuía para o debate ambientado no contexto da publicação do artigo de Paolo Nosella (1981) "O compromisso político como horizonte da competência técnica”, que registra algumas perplexidades suscitadas a partir do livro de Guiomar Namo de Mello, "Magistério

Expressão do próprio Saviani.

Cadernos de Educação, v.20, n. 40, jan.-jun. 2021 
de $1^{\circ}$ grau: da competência técnica ao compromisso político" (1981), Saviani (2013) analisa ambas as obras e se propõe a ir para além daquele debate apontando as aproximações entre as duas teorias, produzindo outro artigo, o qual compõe um capítulo em sua obra "Pedagogia histórico-crítica".

O objetivo aqui será tão somente indicar o ponto de convergência encontrado por Saviani, uma vez que este também converse com a sua própria pedagogia histórico-crítica, que é o conceito de mediação.

A teoria a qual Saviani (2013) denomina como Fruto Proibido, de Nosella (1981), que "temia" a volta do tecnicismo, afirma que a competência técnica não pode ser considerada em si. E a teoria denominada como Pomo da Discórdia, de Namo de Mello (1981), embora parecesse de caráter tecnicista, acaba por afirmar que: "a prática do professor tem sempre um sentido político em si, independentemente de que sentido exista para o professor, isto é independente de que se tenha ou não consciência do significado político da ação educativa." (SAVIANI, 2013, p. 45)

Assim, Saviani (2013) admite que, em última instância, a perspectiva de Nasser (1981) converge com a da Namo de Mello (1981), já que também ele, no fundamental, aceitaria a tese segundo a qual a função política da educação (escolar) se cumpre também, embora não somente, pela mediação da competência técnica:

Com efeito, se esta é a concretização do compromisso político, se é pelo saber-fazer que as intenções sociais gerais se materializam, e se é pela metodologia que atua o compromisso político, então o caráter mediador da competência técnica expressasse aí de modo claro. (SAVIANI, 2013, p. 44)

Complementando essa relação, o autor nos convida a refletir: 
Ora, se o conceito de mediação indica justamente o caráter instrumental da educação e, por consequência, afirmar que a educação é mediação significa admitir que o que passa em seu interior não se explica por si mesmo, mas ganha este ou aquele efeito social dependendo das forças sociais que nela atuam e com as quais se vincula. (SAVIANI, 2013, p. 45)

Temos aí, pois, a convergência com a posição de Namo de Mello (1981), quando Nasser diz que a prática do professor tem sempre um sentido político em si.

Disso decorre um questionamento: quem tem medo do compromisso político? E a resposta, além de aproximar as duas visões apresentadas, também converge para as reflexões propostas por Saviani (2013) no cerne de sua teoria: temem o compromisso político aqueles mesmos que temem a competência técnica. Segundo o autor, as classes dominantes temem o compromisso político transformador, e tendo em vista ampliar o debate acerca da educação, Saviani (2013) se propõe em responder às críticas direcionadas a sua teoria da Pedagogia Histórico-Crítica.

\section{OBJEÇÕES E DICOTOMIAS QUE ENVOLVEM A PEDAGOGIA HISTÓRICO-CRÍTICA}

Do mesmo modo que Saviani se propôs a compreender e a participar do debate que envolveu as teorias de Nasser (1981) e Namo de Mello (1981), também a sua teoria da pedagogia histórico-crítica teve seus questionamentos e objeções, que foram respondidas a partir das seguintes dicotomias apresentadas por Saviani (2013): Forma e conteúdo; Socialização e Produção do Saber; Saber e Consciência; Saber acabado e Saber em processo, e Saber erudito e Saber Popular.

Segundo a objeção representada pela dicotomia "Forma e Conteúdo", a proposta da pedagogia histórico-crítica seria 
conteudista, e, nesse sentido, desconsideraria as formas, os processos e os métodos pedagógicos. No entanto, não é esse o caminho teórico percorrido por Saviani, ao contrário: ele enfatiza que a questão central da pedagogia é a questão dos métodos e dos processos. É daí que surge o problema da transformação do saber elaborado em saber escolar. Essa transformação é o processo por meio do qual se selecionam, do conjunto do saber sistematizado, os elementos relevantes para o crescimento intelectual dos alunos e organizam-se esses elementos numa forma, numa sequência tal que possibilite a sua assimilação.

Assim, uma das questões centrais da pedagogia histórico-crítica é o problema das formas, dos processos e dos métodos, no entanto, certamente, não considerados em si mesmos, pois as formas só fazem sentido quando viabilizam o domínio dos conteúdos. E nessa perspectiva há de se refletir: para que serve ensinar uma disciplina como geografia, história ou Português aos alunos concretos com que se vai trabalhar, se não de modo que tais disciplinas sejam relevantes para o progresso, avanço e desenvolvimento desses alunos.

No que tange à dicotomia representada como: "Socialização e Produção do Saber", Saviani (2013) questiona as "acusações" de críticos que o classificara como teórico durkheimiano, afirmando que falar em socialização do saber elaborado é voltar a Durkheim, que já dizia que a função da escola é socializadora. No entanto, retiramos de sua obra o contraponto:

A produção do saber é social, ocorre no interior das relações sociais. A elaboração do saber implica expressar de forma elaborada o saber que surge da prática social. (...) Essa expressão elaborada supõe o domínio dos instrumentos de elaboração e sistematização. Daí a importância da escola [...] (SAVIANI, 2013, p. 67) 
Assim, o fato de usar a palavra socialização não o torna durkheimiano, mas sim, coerente com sua própria base, que é o materialismo histórico de Marx (1973).

Por tratar da importância do ensino do saber objetivo e sistematizado, levantou-se que a pedagogia histórico-crítica estaria dando mais importância à aquisição do saber do que à consciência crítica, dicotomia apresentada por Saviani (2013) como "Saber e Consciência". Na verdade, porém, Saviani explica que o nível de consciência dos trabalhadores se aprimora e ganha forças à medida que se aproxima de uma forma elaborada, e isso só é possível quando se dominam os instrumentos de elaboração do saber.

A dicotomia "Saber acabado e Saber em Processo" consiste na crítica de que a pedagogia histórico-crítica implicaria em uma visão do saber como algo definitivo e acabado, tratando-se apenas de transmiti-lo. No entanto, facilmente se desmonta tal crítica, uma vez que muito já foi dito como uma das questões centrais da teoria: afirmar a produção social do saber como histórica, e portanto, de forma alguma pode ser pensada como acabada, visto não ser obra de cada geração independente das demais.

Ainda aprofundando esse ponto do debate, Saviani trata de outra dicotomia: "Saber erudito e Saber Popular" (Ponto de partida e ponto de chegada), cuja crítica tem raízes próximas da dicotomia já apresentada que envolve "Saber e Consciência".

Segundo essa crítica, estaria a pedagogia histórico-crítica valorizando a cultura erudita em detrimento da cultura popular e, ao centrar-se no ponto de chegada, estaria desconsiderando o ponto de partida? Não. Saviani (2013) explica que essa dicotomia entre saber erudito como saber da dominação e saber popular como saber autêntico e próprio da libertação é uma dicotomia falsa, pois segundo ela nem o saber erudito é puramente burguês, dominante, nem a cultura popular é puramente popular.

Assim, tendo em vista a natureza e especificidade da educação e questionando-se os contrapontos apresentados pelas 
dicotomias que a circundam a Pedagogia Histórico-Crítica, fica claro que com a expressão "pedagogia histórico-crítica", Saviani buscou traduzir o empenho em compreender a questão educacional com base no desenvolvimento histórico objetivo. Tendo como concepção pressuposta o materialismo histórico, ou seja, a compreensão da história a partir do desenvolvimento material, da determinação das condições materiais da existência humana.

\section{RELAÇÃO DA PEDAGOGIA HISTÓRICO-CRÍTICA COM A REALIDADE ESCOLAR}

Uma vez compreendido que a Pedagogia histórico-crítica tem como pressuposto a concepção dialética da história, levanta-se a possibilidade de trabalhar a educação escolar tal como ela se manifesta no presente, considerando-a, contudo, como resultado de um longo processo de transformação histórica.

Nas palavras de Saviani (2013, p.81):

o que se chama de desenvolvimento histórico não é outra coisa se não o processo através do qual o homem produz a sua existência no tempo. Agindo sobre a natureza, ou seja, trabalhando, o homem vai construindo o mundo histórico, vai construindo o mundo da cultura, o mundo humano.

E é nesse contexto que a educação se desenvolve.

Chega-se assim, à estreita relação da pedagogia histórico-crítica com a realidade escolar, como concepção que surgiu justamente em decorrência de necessidades postas pela prática dos educadores nas condições atuais, que foi desenvolvida para a realidade escolar e é nela que deve ser aplicada a fim de direcionar a atuação da escola, vencendo o paradoxo da escola secundarizada ao mesmo tempo que hipertrofiada. 


\section{PARADOXO: A ESCOLA SECUNDARIZADA $X$ A ESCOLA HIPERTROFIADA}

É de senso comum a afirmativa de que não é só através da escola que se educa, pois existem múltiplas formas educativas, como partidos políticos, associações de bairros, meios de comunicação em massa etc. e a escola seria somente mais uma nesse contexto.

No entanto o que se observa na prática é, ao mesmo tempo, uma jornada na direção de hipertrofiar a escola, de modo vertical, com a tendência de estender o tempo de escolaridade, inclusive também antecipando o seu início, e de modo horizontal, com a ampliação do turno escolar.

\section{A MATERIALIDAdE DA AÇÃo PEDAGÓGICA E OS DESAFIOS DA PHC}

Diante de tantas problemáticas apresentadas, não se pode deixar de abordar que há desafios a serem superados pela pedagogia histórico-crítica. Tais desafios passam pelo campo Teórico, no que diz respeito a desenvolver aspectos que ainda necessitam de maior elaboração, bem como a sistematizar e articular aspectos já abordados a fim de emancipá-los a argumentos ditos totalizantes e coerentes. E pelo desenvolvimento da Prática (práxis) do ensino em sala de aula e, nesse aspecto Saviani cita que recebeu importantes contribuições a partir do livro de João Luiz Gasparin (2002), "Uma didática para a pedagogia histórico crítica".

A fim de promover um aprofundamento na visão de Saviani, e uma melhor compreensão de seus desafios específicos, que serão aqui tratados, é importante que se tenha claro o conceito da materialidade da ação pedagógica.

\section{SOBRE A MATERIALIZAÇÃO DA AÇÃO PEDAGÓGICA}

São duas as modalidades existentes na produção não material: aquela em que o produto se separa do produtor e aquela 
em que o produto não se separa do produtor. O ensino é, pois, uma atividade cujo produto não se separa do produtor e no qual, para seu exercício, é necessário partir de condições materiais e ainda se desenvolve também em condições materiais.

Assim, como analogia à questão da materialidade da educação podemos utilizar o exemplo de um livro, que é um objeto material, mas o que ele contém são ideias, são teorias, portanto algo imaterial. Assim, o produto da elaboração de um livro, que é a ideia, é imaterial, mas elas são veiculadas pela materialidade, por meio do livro físico.

Partamos agora para a análise de três desafios importantes a serem enfrentados: $\mathrm{O}$ desafio relativo à ausência de sistema educacional no Brasil, a questão organizacional e a descontinuidade da ação educativa.

Sobre o desafio relativo à ausência de sistema educacional no Brasil, cabe observar, preliminarmente, que a falta de um sistema educacional em nosso país é uma questão que vem do final do século XIX, dado que a partir daquela época os principais países se empenharam em organizar os seus sistemas nacionais de ensino. Assim, com a não preocupação com a implantação de um sistema nacional de ensino o Brasil desobriga-se de realizar a instrução popular, e por isso acabou gerando um déficit histórico imenso e secular, de tal modo que ainda é um dos países com os maiores índices de analfabetismo.

Disso decorre que, na atualidade, mesmo que se destine um percentual que em termos numéricos nos pareça plausível para o desenvolvimento da educação, isso não irá suprir a necessidade da realidade concreta, já que o déficit histórico deverá ser compensado para cobrir a falta de investimentos preliminares que deveriam ter ocorrido para que hoje fosse possível se pensar em manutenção e desenvolvimento (que pressupõe um sistema implantado e operando).

Considerando-se a questão material da organização do sistema e das escolas, faz-se necessário, portanto, um grau de 
mobilização e organização que pressione o Estado e o conjunto da sociedade, no intuito de que a educação venha a assumir o caráter de prioridade efetiva e com isso os recursos venham a ser destinados.

O desafio é fazer com que tais reivindicações se mobilizem no interior da própria ação pedagógica, desenvolvendo mecanismos que se contraponham a esse estado de coisa. Há, porém, um senso comum que separa teoria e prática, e desencoraja a ação, uma vez que muitos educadores, diante de propostas de reorganização escolar, dos processos curriculares etc., tendem a dizer que tudo não passa de uma teoria que não irá mudar nada na prática.

Há que se combater tal pensamento entendendo que a relação entre teoria e prática é estreita e deve ser explorada no ambiente escolar. Se tomarmos como exemplo as teorias da pedagogia tradicional e a pedagogia nova, podemos observar a prática por meio da observação da configuração da sala de aula que ocorre com base em cada uma dessas linhas.

Como base na pedagogia tradicional temos carteiras enfileiradas, com professor a frente e ambiente silencioso, a fim de reduzir distrações; com base na pedagogia nova as carteiras ficam dispersas, sem mesa do professor, e cartazes multicoloridos a fim de aumentar os estímulos em sala de aula. Com esse exemplo fica fácil entender que existe sim uma ponte que liga a teoria à prática.

Quando se considera o desafio da descontinuidade, outra problemática importante é o fato de que não basta realizar ações pontuais e pouco articuladas, de alfabetização, por exemplo. $\mathrm{O}$ trabalho educativo tem que se desenvolver num tempo suficiente para que as habilidades, os conceitos que se pretendem sejam assimilados pelos alunos, de fato, se convertam numa espécie de segunda natureza.

Isso nos remete à importância de se considerar o aspecto material da educação, pois se faz necessário treino, tempo 
empenhado em repetições, leituras, ditados relacionados a diferentes conteúdos, dentre outros estímulos constantes para que o conhecimento seja efetivado e, isso se dará, principalmente, dentro da escola.

A continuidade é, pois, necessária, e segundo Saviani essa é a base do fracasso das campanhas de alfabetização, por exemplo, já que são esporádicas, descontínuas, e não duram o tempo suficiente para se atingir um ponto de irreversibilidade.

\section{CONSIDERAÇÕES FINAIS}

Tendo este artigo a intenção de trazer luz a aspectos fundamentais da educação, segundo a visão de Saviani, a conclusão a que se chega não pode esgotar nem tampouco reduzir o debate. Contudo, de modo simples e objetivo podemos afirmar: a educação não pode ser pensada somente no campo da teoria, sem que isso se converta para uma prática que se encaixe ao contexto de cada realidade escolar, bem como não pode ser praticada sem que os aspectos sociais sejam considerados. E é por isso que a Pedagogia histórico-crítica surge como uma alternativa plausível, que serve como ponto de partida para aprofundar e nortear o debate que diz respeito à concepção do papel da escola em nossa sociedade.

\section{REFERÊNCIAS}

GASPARIN, J.L. Uma didática para a pedagogia Histórico Crítica. Campinas, Autores Associados, 2002.

SAVIANI, Dermeval. Pedagogia Histórico-Crítica: Primeiras aproximações. 11. ed. Campinas: Autores Associados, 2013

SAVIANI, D.A. A Pedagogia Histórico-Crítica. Revista Binacional Brasil Argentina, Conferencia realizada no Centro Regional de Professores do norte, Rivera, Uruguai, em 28/04/2011. Com revisão do autor. Vitória da Conquista, 2014, V. 3 n. 2 , p. 11 a 36.

SAVIANI, Dermeval. Escola e democracia, 41. ed. Campinas: Autores Associados, 2009.

MARX, Karl. Contribuição para a crítica da economia política. Lisboa: Estampa, 1973. 